\title{
SLURRY OPTIMISATION FOR FAST FREEZE-DRYING OF POROUS ALUMINA
}

\author{
"KRITKAEW SOMTON, KANNIGAR DATERAKSA, PITAK LAORATANAKUL \\ National Metal and Materials Technology Center, National Science and Technology Development Agency, \\ 111 Thailand Science Park (TSP), Phahonyothin Road, Khlong Nueng, Khlong Luang, \\ Pathumthani 12120, Thailand \\ "E-mail: kritkaes@mtec.or.th
}

Submitted July 21, 2021; Accepted October 11, 2021

\begin{abstract}
Keywords: Porous alumina, Freeze dry, Freeze casting, Solid loading
The optimisation of alumina foam slurries for fast freeze-drying was determined and the final properties of the porous specimens were examined. The slurry solid loadings were varied from 50, 60, and $70 \mathrm{wt}$. \%. The impact of a foaming agent (a naturally modified anionic surfactant), which generated bubbles, was investigated comparing samples without the foaming agent and with a $5 \mathrm{wt}$. \% foaming agent. The amount of binder (polyvinyl alcohol) was varied from 5 and $10 \mathrm{wt}$. \%. It was found that increasing the slurry solid loadings and the binder content resulted in a slower freeze-drying. This was due to the difficulty in breaking the bonds between ice crystals and the binder molecules during sublimation. Also, the high solid loadings decreased the porosities and narrowed the pore channels causing ice crystals to be trapped, which slowed down the process. A foaming agent addition could shorten the freeze-drying duration up to $25 \%$ when the binder was present with no more than $5 \mathrm{wt} . \%$. Therefore, the optimised formula found in this study was B5F5_60, which showed a porosity of $76 \%$ and a strength of $4 \mathrm{MPa}$. This indicates that a highly porous material can be achieved with a fast freeze-drying technique.
\end{abstract}

\section{INTRODUCTION}

Freeze casting is one of the colloidal processing techniques that has recently become an attractive solution for producing various kinds of porous ceramic products. This is because it is a simple process that does not produce cracks while drying. It does not require a large binder burnout process compared to other conventional colloidal processes, e.g., slip casting, injection moulding, gel casting etc. $[1,2]$. Also, the technique can provide a broad range of porosities, even higher than $90 \%$, with a well-controlled pore structure [3, 4]. Hence, it is used in various applications, such as insulators, absorbers, filters, heat exchanger, and energy harvesting applications [5, 6]. Although the freeze casting technology shows many beneficial aspects, a drawback is that it is time-consuming during the freeze-drying process. The freeze-drying process could take days or even weeks for sublimation if the freeze-drying cycle was not optimised [7]. Heating the product during freeze-drying could shorten the drying process. However, this leads to defrosting and the collapse of the internal structure if the temperature of the dry layer exceeds the critical temperature of the products $[8,9]$. Another way of quick freeze-drying is to increase the surface areas of the components. High porosity samples could be obtained by incorporating polymeric additives to generate foam in the suspension before freeze-drying. To the best of our knowledge, there are few reports on this aspect. For example, from the research of Yao D. [10], porous $\mathrm{Si}_{3} \mathrm{~N}_{4}$ was freeze-dried in 12 hours using a technique of bubble generation from ball milling slurry with $5 \%$ polyvinyl alcohol (PVA) combined with a technique of bubble expansion from vacuuming the slurry. However, the relationship between the material processing and the freeze dry duration was not investigated. Therefore, reducing the time in the freeze-drying process by this technique was a primary motivation of this study. The material chosen for this study is alumina because it is used in many industries, such as the automotive industry, chemical plants, refractories, and so on, where the properties of high strength, high heat and wear resistance of the materials are primarily focused. Moreover, some products, such as kiln furniture that are used in furnaces, require light-weight and high-strength properties. Therefore, porous alumina is one of the candidate materials for such applications. We investigated freeze-drying on alumina ceramics by varying the solid contents from 50,60 , and 70 wt. \%. In order to minimise the drying duration, we added a binder (PVA) and a foaming agent (a naturally modified anionic surfactant) into the ceramic slurries to generate bubbles by a direct foaming method to increase the surface area of the solvent vapour to enhance the sublimation. The amounts of the binder (5 and $10 \mathrm{wt} \%$ ) and foaming agent $(0$ and 5 wt. $\%)$ that impacted the properties of the sintered porous ceramics were optimised with an objective of reducing the manufacturing time and cost. 


\section{EXPERIMENTAL}

The ceramic powder used in this study was alumina (A-32, Nicho CO., LTD) with an average particle size of $4.04 \pm 0.03 \mu \mathrm{m}$. The PVA powder (Gosenole, Y.S. INC., Japan), with a molecular weight of 146 000-186000 according to the manufacturer, was used as an additive binder. A naturally modified anionic surfactant consisted of sulfuric acid, a mono-C9-13-alkyl ester, and sodium salt (Sikaporo-40, Sika (Thailand) Limited) was used as an additive foaming agent. Ammonium polyacrylate (Aron A-6114, Japan) was used as a dispersing agent. Water was used as the solvent. In order to determine the freeze-drying conditions and the precursor characteristics, the raw materials were separately mixed with water. The alumina was mixed with the water to form the slurry with the solid loadings of 50, 60, and 70 wt. \%. The 5 and 10 wt. $\%$ of PVA were mixed in water to make the solutions. A differential scanning calorimetry (DSC: Metter, model DSC822e) analysis was conducted to find the crystallisation temperatures of the alumina slurries' precursors and the PVA solutions.

The PVA solutions were dried at room temperature to obtain thin films. The alumina powder was compacted to form a thin plate for the Fourier transform infrared spectroscopy (FTIR: Nicolet, model Impact 400) analysis in the attenuated total reflectance (ATR) mode at a spectrum range of $600 \mathrm{~cm}^{-1}$ to $4000 \mathrm{~cm}^{-1}$. Once the studied precursors were completed, the alumina slurries of the three solid loadings were mixed with either 5 or 10 wt. \% PVA (a total of six set samples). The effects of the foaming agent were studied by adding $5 \mathrm{wt} \%$ into each sample compared to without the foaming agent (0 wt. \%). A 0.9 wt. \% dispersant was used in all the slurry conditions. The compositions and sample labels are shown in Table.1. The mixtures were stirred with a highspeed rotator at $1700 \mathrm{rpm}$ for 5 minutes so that foams were generated. The rheology of the slurries was investigated by a viscometer (Brookfield, model DV-II+). The specific gravities were calculated from the weight and volume fractions of the slurries in graduate cylinders. Then, the slurries were poured into a bar-shaped silicone mould with a size of $4 \times 33 \times 6 \mathrm{~mm}$. The slurries were solidified by freezing in the freezer (SANYO, model SF-C697) at $-20^{\circ} \mathrm{C}$ for 5 hours.

The frozen samples were taken out of the freezer and quickly loaded into the freeze dryer machine (CHRIST, model Alpha 2-4 LSC). Lyophilisation was conducted at a constant temperature and pressured conditions, which were selected from the DSC study. The freezedrying duration took 2 - 72 hours. The moisture contents were measured every 2 hours or until the slurries were dried to become porous green alumina samples. The green densities were calculated by the weight and volume fraction of the measured size of the samples. The samples were sintered in an electric furnace (HP Advanced ceramic furnace, Thailand) at $1600{ }^{\circ} \mathrm{C}$ for 2 hours at a heating rate of $5^{\circ} \mathrm{C} \cdot \mathrm{min}^{-1}$ and the porosity was determined using the Archimedes method. The pore size distributions of the sintered samples were analysed by mercury intrusion porosimetry (MIP) (Micomeritics, model V9600). The flexural strength was measured by a mechanical tester (Instron, model 8872) with 3-point bending and a loading rate of $0.5 \mathrm{~mm} \cdot \mathrm{min}^{-1}$. The morphologies of the porous samples were examined using a scanning electron microscope (SEM, Hitachi, model S-3400N). The SEM samples were polished, gold coated, and observed in the SEM with the secondary electron mode.

\section{RESULTS AND DISCUSSION}

\section{Precursor properties}

The DSC of the precursor alumina slurries with the solid loadings of $50,60,70 \%$, the foaming agent solution, and the binder solutions with concentrations of $5 \%$ and $10 \%$ are shown in Figure 1 . The onset temperature for the crystallisation of the alumina precursors was $-9{ }^{\circ} \mathrm{C}$ while those of the polymer solutions were below $-19{ }^{\circ} \mathrm{C}$. This indicated that the energy used to freeze the alumina was lower than the polymer additives. From the DSC results, a freeze-drying temperature was selected to be at $-50^{\circ} \mathrm{C}$ in order to ensure that the overall freezedrying chamber temperature was not higher than the crystalline precursor temperature. Also, a pressure of 0.04 mbar was chosen from the "Table of ice vapour pressure" in ref. [11] at which the temperature was $-50{ }^{\circ} \mathrm{C}$.

The FTIR spectra of the alumina powder, $5 \%$ and $10 \%$ PVA solutions are shown in Figure 2. The broad peak of the PVA spectrum around 3330-3400 $\mathrm{cm}^{-1}$ corresponds to the stretching vibration of the $-\mathrm{OH}$ group $[12,13]$. The peaks at wave numbers $2850-2922 \mathrm{~cm}^{-1}$ are the stretching vibration of the $\mathrm{C}-\mathrm{H}$ group. The bands at $1732 \mathrm{~cm}^{-1}$ and $1568 \mathrm{~cm}^{-1}$ are attributed to the $\mathrm{C}=\mathrm{O}$ and $\mathrm{C}=\mathrm{C}$ vibrations, respectively. The other vibrations at $1240-1424 \mathrm{~cm}^{-1}$ and $1087 \mathrm{~cm}^{-1}$ are assigned to $\mathrm{C}-\mathrm{H}$ and

Table 1. Compositions and labels of the alumina slurries with the different binder and foaming agent amounts.

\begin{tabular}{ccccc}
\hline \multirow{2}{*}{$\begin{array}{c}\text { Slurry solid } \\
\text { loadings (wt. \%) }\end{array}$} & \multicolumn{2}{c}{ PVA Binder 5 wt. \% } & \multicolumn{2}{c}{ PVA Binder 10 wt. \% } \\
\cline { 2 - 5 } & Foam 0 wt. \% & Foam 5 wt. \% & Foam 0 wt. \% & Foam 5 wt. \% \\
\hline 50 & B5F0_50 & B5F5_50 & B10F0_50 & B10F5_50 \\
60 & B5F0_60 & B5F5_60 & B10F0_60 & B10F5_60 \\
70 & B5F0_70 & B5F5_70 & B10F0_70 & B10F5_70 \\
\hline
\end{tabular}

Ceramics - Silikáty 65 (4) 368-376 (2021) 
$\mathrm{O}-\mathrm{C}-\mathrm{O}$, respectively [14]. PVA5 and PVA10 had nearly identical peak patterns except at the $1568 \mathrm{~cm}^{-1}$ wave number where the PVA10 peak was slightly higher than that of the PVA5 one. The high peak absorption indicated more intermolecular and intramolecular hydrogen bonds in the PVA [15]. The FTIR spectrum of the foaming agent displayed bands at $2800-3000 \mathrm{~cm}^{-1}$ and $1467 \mathrm{~cm}^{-}$ ${ }^{1}$, which are attributed to the $\mathrm{C}-\mathrm{H}$ stretching and bending vibration. The band at $950-1250 \mathrm{~cm}^{-1}$ corresponds to the $\mathrm{S}=\mathrm{O}$ stretching vibration [16-18]. This indicated that the structure of the foaming agent consisted of a hydrophobic hydrocarbon tail and a negative charged hydrophilic sulfonate $\left(\mathrm{OSO}_{3}{ }^{-}\right)$head. The hydrogen bonding network can interact between this hydrophilic head and the $-\mathrm{OH}$ molecule of water $[19,20]$. The FTIR of the alumina shows a significant absorption band at $640 \mathrm{~cm}^{-1}$ which is identified to be the characteristic absorption bands of $\alpha-\mathrm{Al}_{2} \mathrm{O}_{3}$. The other peaks of very weak intensities at $3466 \mathrm{~cm}^{-1}$ and $2924 \mathrm{~cm}^{-1}$ are the $-\mathrm{OH}$ and $\mathrm{C}-\mathrm{H}$ stretching vibrations, respectively [21].

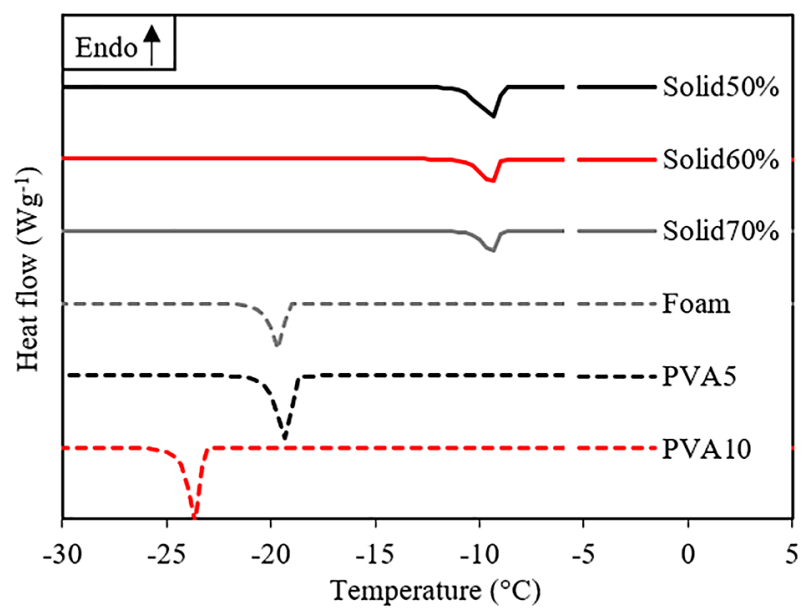

Figure 1. DSC analysis of the precursors of the varied concentrations of the alumina slurries, foaming agent, and PVA solutions.

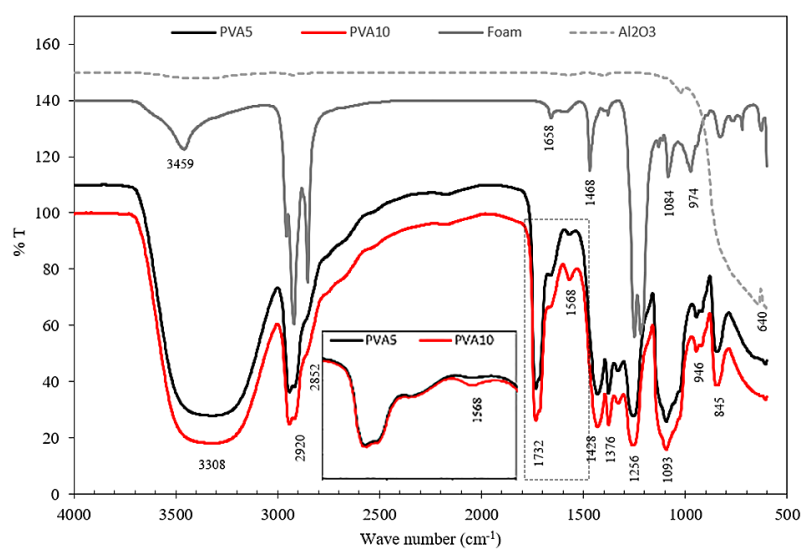

Figure 2. FTIR of the 5 wt. \%, and 10 wt. \% PVA solutions, foaming agent, and alumina powder.
The FTIR results indicated that, in the alumina slurry system, the hydrogen bonding of the PVA and the foaming agent had much stronger bonds to the water molecules than $\mathrm{Al}_{2} \mathrm{O}_{3}$. In fact, $\mathrm{Al}_{2} \mathrm{O}_{3}$ theoretically does not dissolve in water. Therefore, any effect from the water sublimation during the freeze-drying is not likely to be related with the bonding interaction between the alumina and the water molecules. It is more likely to be the effect from the bonding between the polymeric additives and the water molecules.

\section{Slurry properties}

The viscosities, in a logarithmic scale, of the alumina slurry are shown in Figure 3. All the slurries exhibited shear thinning behaviour. The viscosities of B5F0_50 and B10F0_50 (Figure 3a) were similar. This indicated that the addition of the binder content from 5 to $10 \mathrm{wt} . \%$ at the solid loading of $50 \mathrm{wt}$. \% did not significantly affect the rheology of the slurries. A further increase in the slurry solid loadings and the binder contents resulted in an increase in the viscosity. The slurries with the foaming agent of 5 wt. \% (Figure $3 \mathrm{~b}$ ) showed the same pattern of viscosity increase as the slurry without the foaming agent. It was also observed that the viscosity of all the slurries increased when adding the $5 \mathrm{wt}$ \% foam content.

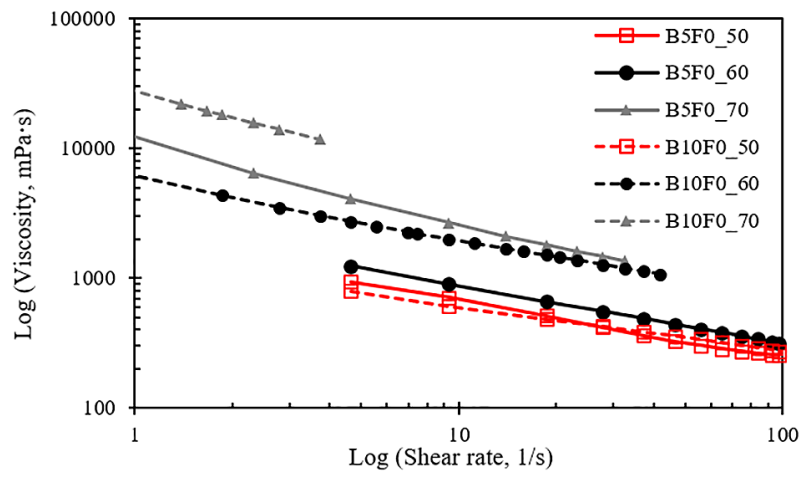

a)

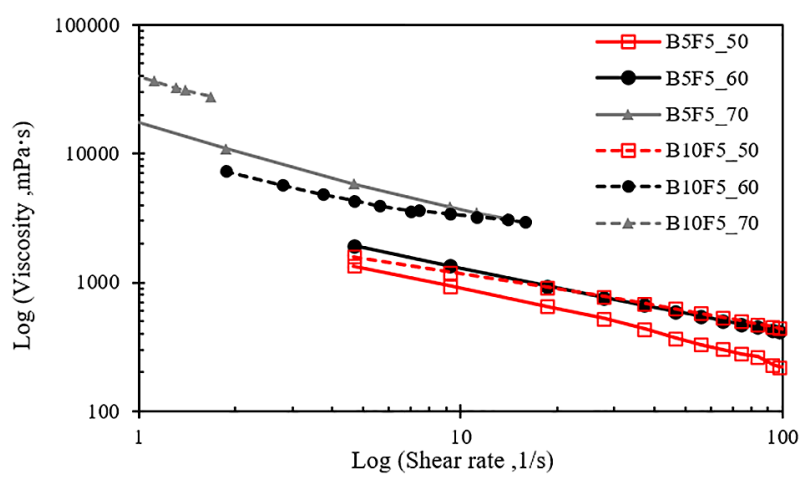

b)

Figure 3. Viscosity, in a logarithm scale, of the alumina slurries without the foaming agent (a) and with the foaming of $5 \mathrm{wt} \%$ (b). The solid loadings were 50,60 , and $70 \mathrm{wt} . \%$ and the binder contents were 5 and 10 wt. \%. 
The effects of the slurry rheology on the slurry specific gravities are shown in Figure 4 . For the B5F0 set, the specific gravity increased from 0.48 to $1.46 \mathrm{~g} \cdot \mathrm{cm}^{-3}$ with the increasing slurry solid loading from 50 to $70 \mathrm{wt}$ \%. For the B5F5 and B10F0 sets, the specific gravities were also increased from 0.35 to 1.01 and 0.73 to 1.38 , respectively. In the B10F5 set, the samples showed an increase in the specific gravity from 0.73 to 1.05 when the solid loading increased from 50 to $60 \mathrm{wt}$. \%. A further increase in the solid loading to $70 \mathrm{wt}$. \% caused a reduction in the specific gravity to 0.85 . It can be concluded that the addition of the foaming agent, while having a low binder content of $5 \mathrm{wt} \% \%$, could increase the slurry volume expansions, hence decreasing the specific gravity. An increase in the binder content to $10 \mathrm{wt}$. \% prohibited the expansion of the bubble volumes in the slurries and resulted in an increase in the specific gravity. In the high solid loadings of $70 \mathrm{wt} . \%$, the addition of the 10 wt. $\%$ binder ruined the homogeneity of the slurries due to the high viscosity, which led to a decrease in the specific gravity.

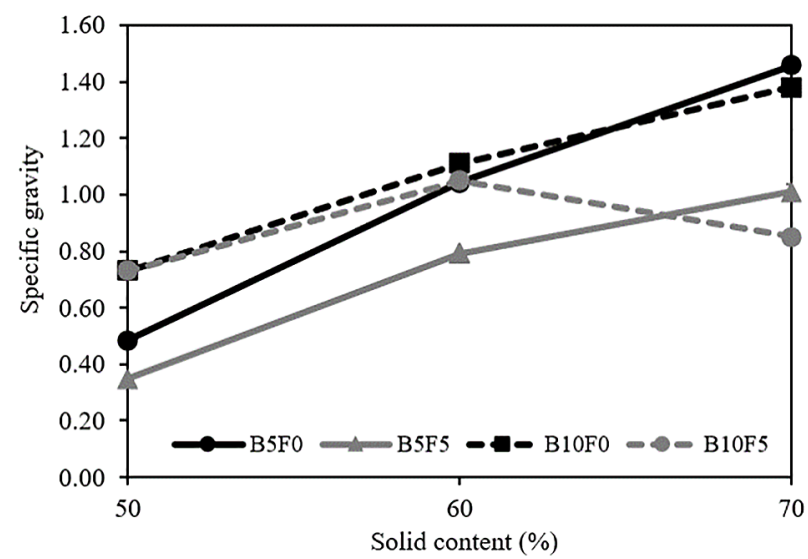

Figure 4. Specific gravities of the alumina slurries with the varied alumina solid loadings, foaming agent, and binder contents.

\section{Freeze dry durations}

The variation in the moisture contents in the slurries as a function of the freeze-drying time are shown in Figure 5. All the slurries showed an increase in the drying time when the solid loadings increased. This is due to the narrowed pore channels trapping the ice/vapour from the sublimation. During the freezing process, the alumina content in the slurry was responsible for controlling the ice crystal growth. As the solid loading increased, the force between the alumina particles was higher than the force between the alumina/liquid compression. Therefore, it was difficult for the particles to be squeezed through the moving ice front. This resulted in a narrowing of the ice channels and increased the densities of the frozen samples. This could also be described by the freeze dry time equation proposed by Steinbach [22] where the drying time was varied proportionally to the density of the frozen product. The increase in the binder content was also responsible for the increase in the freeze dry duration. This was due to the increase in the amount of hydrogen bonding in the PVA molecules as previously stated in the FTIR results. These molecules are bound with the $-\mathrm{OH}$ molecule of water, thus, the amount of free water molecules was reduced. Therefore, the enthalpy of vaporisation of the bound water is considerably higher than that of the pure or free water [23]. As a result, a higher amount of energy was needed to break the bond during sublimation. The addition of the foaming agent, in fact, increases the amount of hydrogen bonding between the hydrophilic head parts of the foaming and the $-\mathrm{OH}$ molecule of water as previously described, which could be affected due to the longer freeze-drying duration. However, the results indicated that the addition of the foaming agent from 0 to $5 \mathrm{wt}$. \% (Figures $5 \mathrm{a}$ and $5 b)$ could shorten the drying duration only when the binder content was 5 wt. \%. This is perhaps due to the enlargement of the bubble size when adding the foaming agent which increases the surface area of the sublimation. The drying time could speed up by 20,25 , and $50 \%$

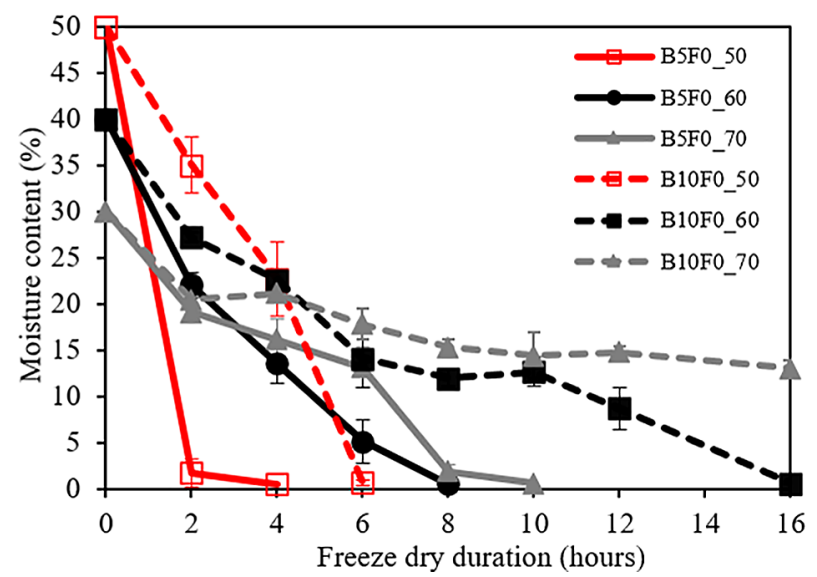

a) 0 wt. $\%$ foam

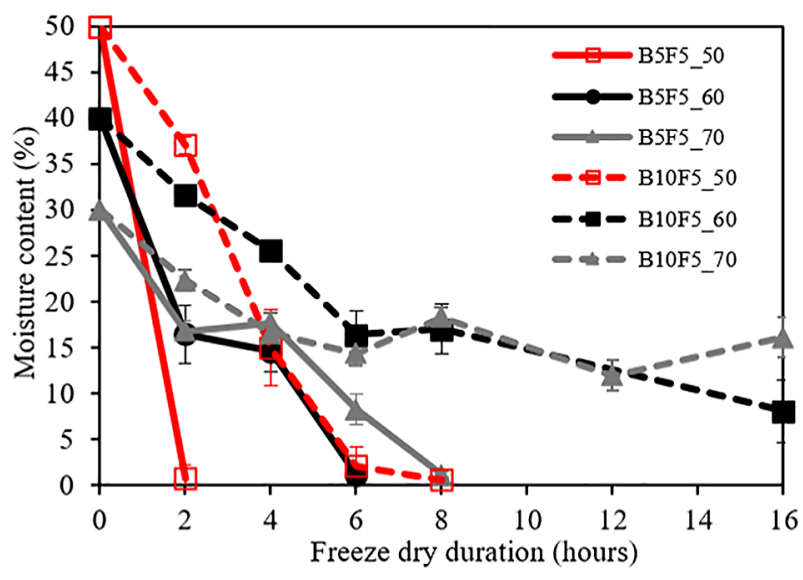

b) 5 wt. $\%$ foam

Figure 5. Freeze dry durations of the alumina slurries with the 0 wt. $\%$ foam (a) and 5 wt. $\%$ foam (b). 
when incorporating the $5 \mathrm{wt} . \%$ foam in the 70,60 , and 50 wt. \% solid loadings slurries, respectively.

The green densities of the freeze-dried products can be seen in Figure 6. All the samples showed an increase in the green densities with the increasing slurry solid loadings. The B5F0 set had a higher value of green density than the B5F5 set for all the ranges of solid loadings. The samples of the $10 \mathrm{wt}$. \% binder set (B10F0, B10F5) had a higher green density value than the 5 wt. \% binder set (B5F0, B5F5). This correlates with the results from the specific gravity part. The only difference in these green density results and the specific gravity results is that B10F5 sample had an increases value in the green density when the slurry solid loading increased from 60 to $70 \mathrm{wt}$. \% which is opposite to the specific gravity result. This is because the high solid loading of the slurry is dominated by the ceramic materials rather than the water content. After the ice was sublimated, the high amount of dry solid materials took effect in the incrementation of the green density. There is one thing that both results have in common: the green density of B10F5 70 has the highest standard deviation value of $\pm 0.12 \overline{\mathrm{g} \cdot \mathrm{cm}^{-3}}$ while the other samples showed no more than $\pm 0.05 \mathrm{~g} \cdot \mathrm{cm}^{-3}$, indicating that the B10F5 70 sample is the most inhomogeneous sample, which resulted from an inhomogeneous slurry formulation.

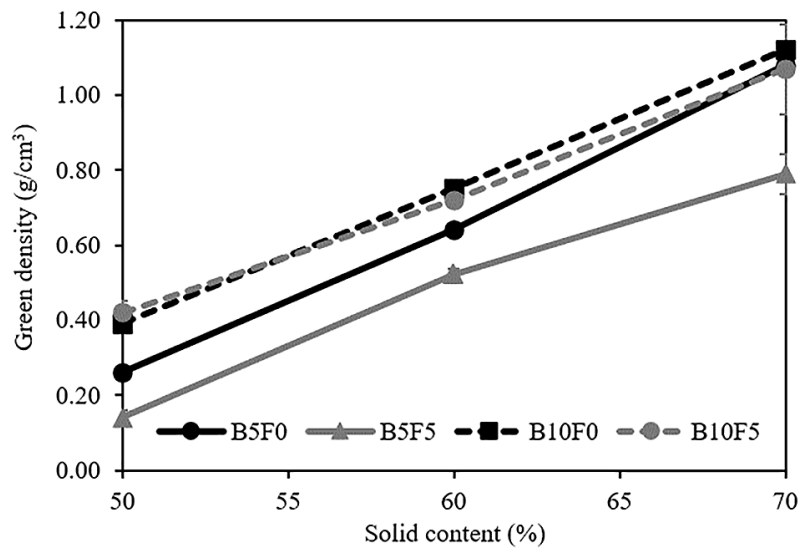

Figure 6. Green gravities of the alumina samples with the varied alumina solid loadings, foaming agent, and binder contents.

\section{Sintered porous alumina}

Figure 7 shows the relationships between the solid loadings of the slurries and the porosities of the sintered porous alumina. The porosities decreased with the increasing solid loadings. This was due to the narrowing of the ice channels from the freezing of the slurries as explained previously. This finding agreed with the study by Wang F. [24]. The B5F5 porosity was the highest for all the ranges of the solid loadings. This is because the foaming agent helps expand the bubbles in the slurry, causing a reduction in both the slurry specific gravity and the green density of the freeze-dried samples. The 10 wt. $\%$ of the binder (B10F0, B10F5) showed lower porosity values than the $5 \mathrm{wt} \%$ binder (B5F0, B5F5) because the increase in the binder content could suppress the bubble expansion. The B10F5 porosity at the 70 wt. \% solid loading (B10F5_70) was equal to that of B5F5_70 due to the fact that the B10F5_70 sample was a non-homogenous slurry containing numerous air gaps in the sample.

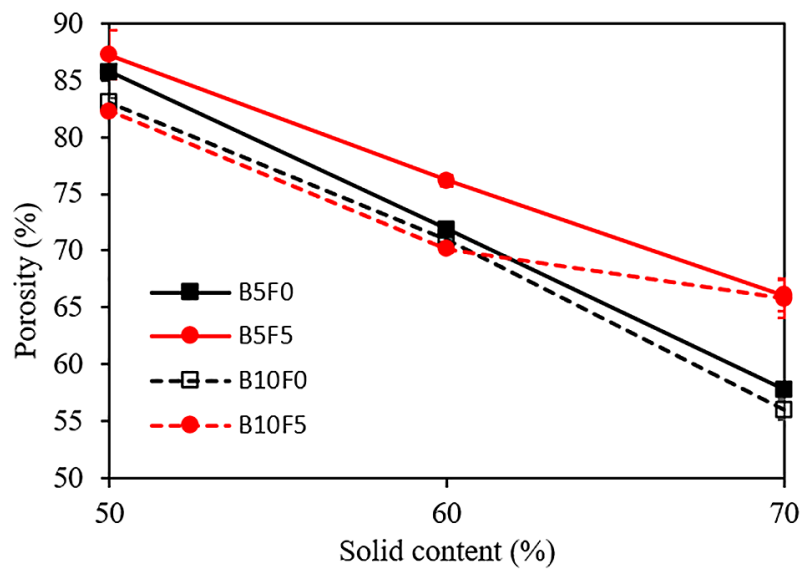

Figure 7. Relationships between the slurry solid loadings and the porosities of the sintered porous alumina.

The pore volume and size distributions, calculated from mercury intrusion porosimetry (MIP), are shown in Figure 8 . The 5 wt. \% binder sets show that an increase in the solid loadings from 50 to $70 \mathrm{wt}$ \% (from B5F0_50 to B5F0_70) decreased the cumulative intrusion volume curve as seen in Figure $8 \mathrm{a}$. The use of the 5 wt. $\%$ foaming content in the 70 wt. $\%$ solid loading (B5F5_70, B10F5_70) shows the cumulative intrusion volume curves, which are higher than those without the foaming agent (B5F0_70, B10F0_70). The distributions of the pore sizes are seen in Figure $8 \mathrm{~b}$. All the samples show peaks in a pore size range of $0.18-0.40 \mu \mathrm{m}$, corresponding to the inter-particle pores between the alumina particles [25]. The samples B5F0_50, B5F0_60, and B5F0 70 show peaks in a pore size range of 10 $100 \mu \mathrm{m}, \overline{5}-50 \mu \mathrm{m}$, and $1-10 \mu \mathrm{m}$, respectively. This indicated that an increase in the solid loadings decreased the pore volume and pore size. B5F5_70 showed peaks at a pore size range of $1-100 \mu \mathrm{m}$, which was wider than that of B5F0_70. Also, the pore size range of B10F5 70 was $0.4-100 \mu \mathrm{m}$, which was wider than $\mathrm{B} 10 \mathrm{~F} 0-70$ $(0.4-6 \mu \mathrm{m})$. This indicated that the addition of the $\overline{5} \%$ foaming content increased the pore volume and pore size. It was also observed that the pore size range of B5F0_70 was wider than B10F0_70. This indicated that an increase in the binder content decreased the pore volume and pore size. B5F5 70 and B10F5 70 had nearly identical pore size ranges due to the non-homogeneity of the B10F5_70 sample. The results obtained from the MIP technique all 
agree with the porosity findings as previously explained. It is noted that the obtained pore size results by the MIP technique may not represent the exact size of the pores in these samples because the calculation is based on the assumption that all the pores are perfectly cylindrical shapes. However, this finding is essential to predict the trends of the pore distributions regarding the variation in the solid loadings and polymeric contents of this experiment.

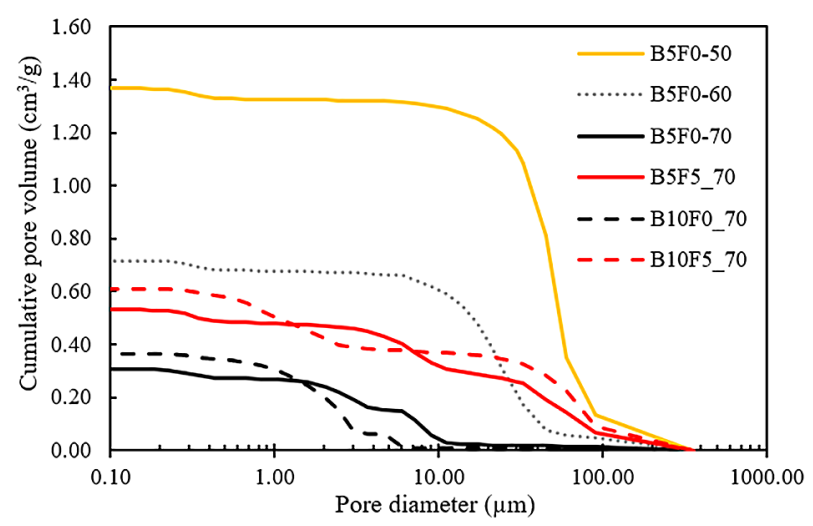

a) 0 wt. $\%$ foam

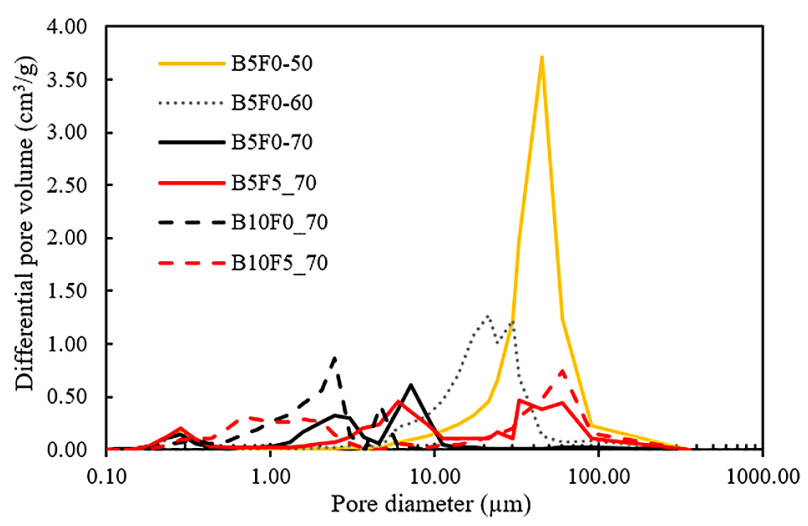

b) 5 wt. $\%$ foam

Figure 8. Cumulative pore volume curves (a), and differential pore size distributions (b) of the sintered porous alumina with the varying solid loadings, binder contents, and foaming contents.

Figure 9 shows the relationships between the solid loadings and the flexural strength of the sintered porous alumina. At the slurry solid loading of $50 \mathrm{wt} . \%$, the strength of the samples with the 5 wt. \% binder (B5F0 50 and the B5F5 50) was very weak and near collapsing from handling. The strength value was lower than $1 \mathrm{MPa}$. The strength of the samples with the 10 wt. $\%$ binder (B10F0_50, B10F5_50) was slightly higher than the $5 \mathrm{wt} \%$ binder samples. This was because the high amount of binder could suppress the bubble expansion which later reduced the porosity and increased the strength. When the solid loadings increased to 70 wt. $\%$, the strength was also increased. At the slurry solid loading of $70 \mathrm{wt} . \%$, the strength of the samples without the foaming agent (B5F0_70 and B10F0 70) was significantly higher than that of the $5 \mathrm{wt}$ \% foaming agent (B5F5 70 and B10F5 70). This was attributed to the increase in the solid content in the materials. An excessive addition of a polymeric additive could cause a very high viscosity in the solution, which would result in the uneven pore structure of the freeze-dried sample and a decrease in the strength.

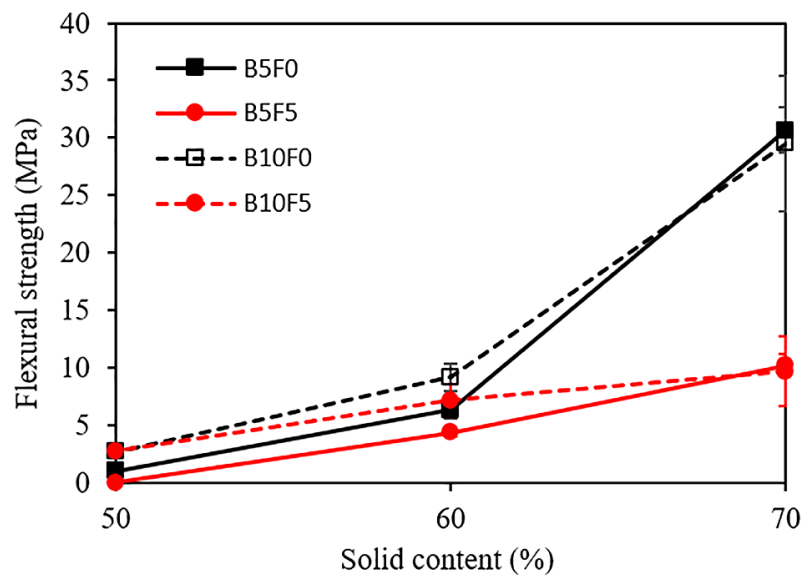

Figure 9. Relationships between the slurry solid loadings and the flexural strengths of the sintered porous alumina.

The microstructures of the sintered bodies are shown in Figure 10. All the samples had a spherical pore shape, which resulted from the generation of bubbles during stirring slurries. These types of pores are called channels. These channels were attached and separated by wall channels. There were numerous small pores distributed inside the wall channels whose structure was dendritic, replicating that of the ice crystals [26]. The B5F0 50 sample (Figure 10a) showed a channel size of $208 \pm 77 \mu \mathrm{m}$. The sample had a loosely packed solid pore structure because the majority of the water content in this slurry composition was sublimated. The B5F0_70 sample (Figure 10b) showed a channel size of $100 \pm 26 \mu \mathrm{m}$. There were small dendritic pores distributed inside the wall channels with a size of $7 \pm 4 \mu \mathrm{m}$ (Figure 10c). These pores were not in any alignment because there was no control of the ice crystals growing direction during the freezing of the slurries. The $70 \mathrm{wt}$. \% solid loading slurries had narrower pores than the $50 \mathrm{wt}$ \% solid loadings indicating the difficulty of the ice-vapour to escape during the freeze-drying as explained previously. The B5F5_50 and B5F5 70 samples (Figures 10d,e) showed a channel size of $582 \pm 122 \mu \mathrm{m}$, and $348 \pm 55 \mu \mathrm{m}$, respectively. It was confirmed that the addition of the foaming agent increased the channel size in the samples. The B5F5_50 sample had a more loosely-packed solid pore structure than the B5F5_70 sample. The B10F0_50 sample (Figure 10f) showed a channel size of $12 \overline{1} \pm 36 \mu \mathrm{m}$. The B10F0_70 sample (Figure 10g) showed an average channel size of $69 \pm 23 \mu \mathrm{m}$ and a few larger channel sizes 
of $293 \pm 132 \mu \mathrm{m}$. This indicated that the non-homogeneity of the B10F0_70 sample occurred due to the use of the high solid loadings and the high amount of binder. The B10F5 50 sample (Figure 10h) showed a channel size of $174 \pm 168 \mu \mathrm{m}$. The B10F5 70 sample (Figure 10i) showed a channel size of $279 \pm 145 \mu \mathrm{m}$, however, some area of the sample showed a size larger than $1000 \mu \mathrm{m}$ and could be observed without using the SEM. So, it is clear that using a large amount of polymeric additives in the high solid loadings of the slurry caused the non-homogeneity of the slurry and affected the non-uniform pore sizes in the freeze-dried samples. It could be observed that the B10F0 and B10F5 samples had a smaller channel size than that of the B5F0 and B5F5 samples, for all the solid loading ranges. This confirmed that the addition of a binder could help suppress the bubble growth in the slurry. In addition, the B5F5 samples showed the highest average pore size for all the solid loading ranges. This proved that the incorporation of the $5 \mathrm{wt}$ \% foaming agent and the 5 wt. $\%$ of the binder in the alumina slu- rries increased the bubble size, reduced the specific gravity, hence, increased the surface area of sublimation, and shortened the freeze dry durations even though the polymeric additives had an ability to chemically bond with water. Finally, a high porosity and adequate strength could be obtained by using the B5F5 compositions.

From the results, it was obvious that the increase in the porosity resulted in a reduction in strength. Therefore, the selection of an appropriate slurry formulation depends on the desired application of the final products. The optimised formula, for this study, is B5F5_60 because it provided a quick freeze dry time, which was $25 \%$ faster than the other samples with the same solid loading. It generated a high porosity $(76 \%)$ with adequate strength for handling (4 MPa). In summary, alumina could be formed with a desired pore size, density, and strength by simply adding appropriate binder and foaming agent amounts to increase the alumina surface area. A freezedrying process could also be obtained quickly and at low cost so that the large-scale production would be possible using this technique.

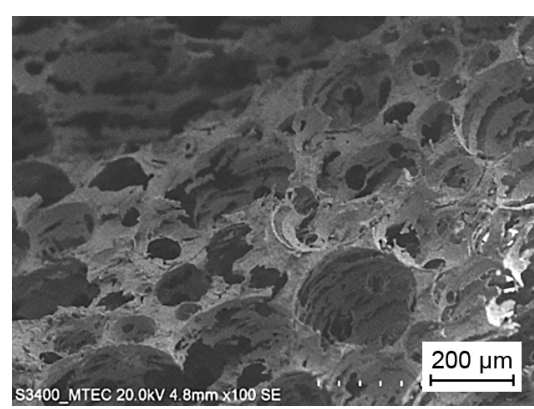

a)

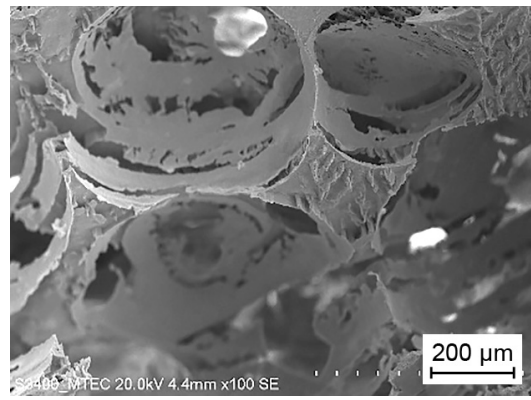

d)

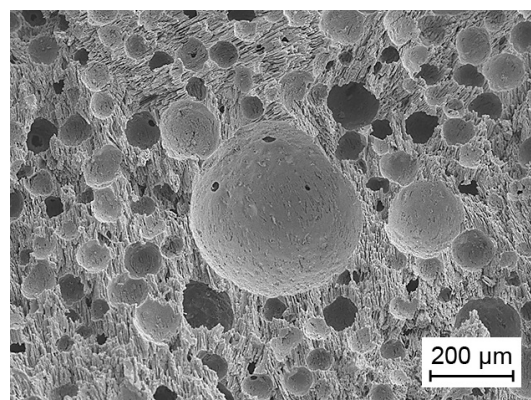

g)

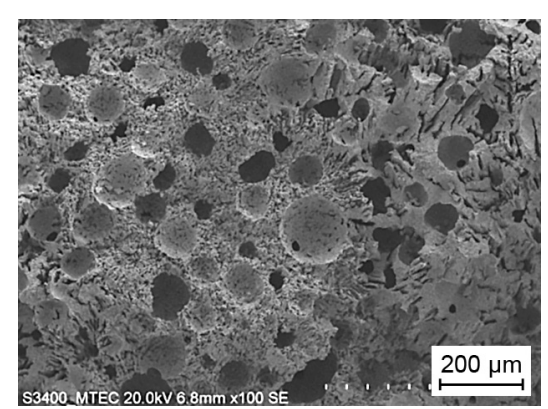

b)

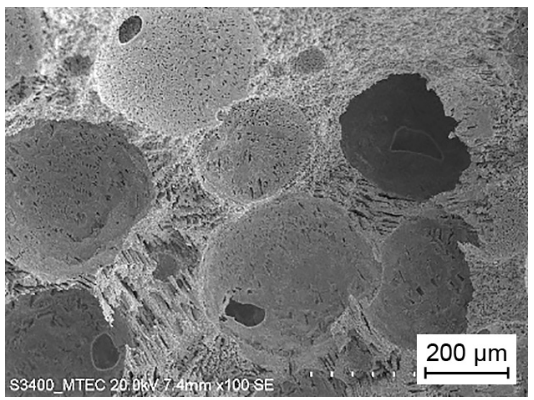

e)

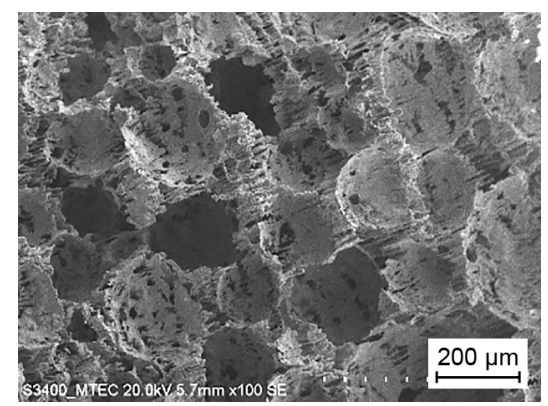

h)

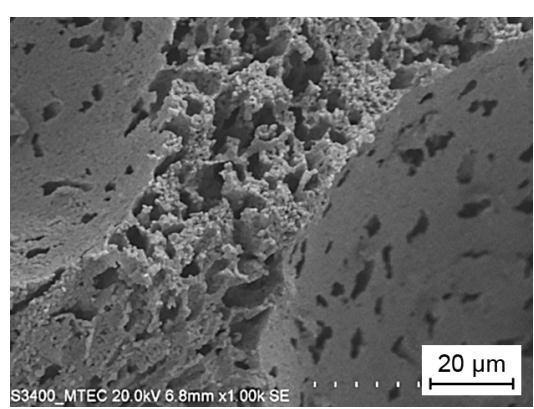

c)

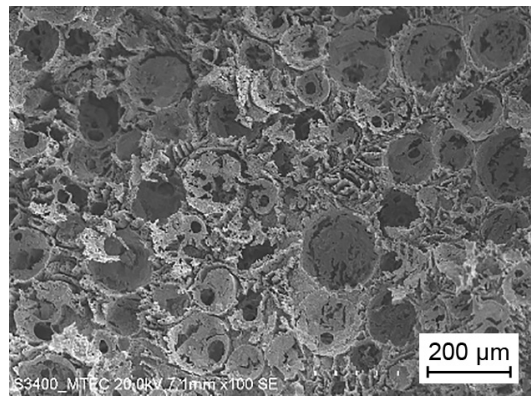

f)

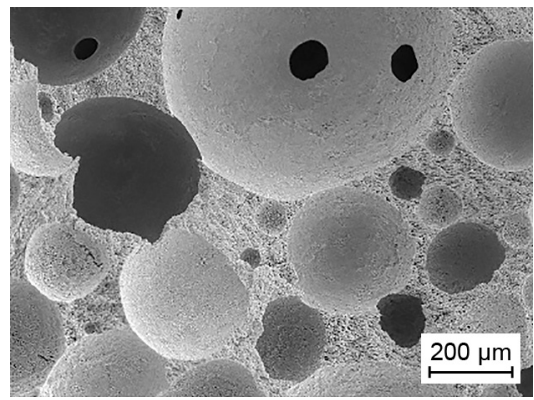

i)

Figure 10. SEM images of the porous alumina samples obtained from the freeze-dried slurries, labelled as B5F0_50 (a), B5F0_70 (b), B5F0_70 zoomed into the small channels (c), B5F5_50 (d), B5F5_70 (e), B10F0_50 (f), B10F0_70 (g), B10F5_50 (h), and B10F5_70 (i). 


\section{CONCLUSIONS}

The optimisation of the slurry solid loadings, the foaming agent, and the binder contents to obtain the shortest freeze dry durations of porous alumina, including the properties of sintered products can be summarised as:

- The high solid loadings took a long time during the freeze-drying process due to the difficulty of the icevapour escaping through the narrowed pore channels in the low porous samples.

- An increase in the binder contents in the slurries caused a long freeze dry duration due to the high energy needed to break the hydrogen bond between the water and the binder molecules.

- Adding foaming agents in the 5 wt. \% PVA mixtures improved the freeze dry duration because the surface areas of sublimation were increased. However, adding them in the $10 \mathrm{wt}$ \% PVA mixtures caused a long duration for the freeze-drying due to the hydrogen bonding matter from all the polymeric additives.

- An increase in the solid loadings and binder content decreased the amount of porosity and pore size of the sintered samples, hence, increased the flexural strengths. The addition of the $5 \mathrm{wt} . \%$ foaming agent caused an increase in the porosities and pore sizes, which decreased the flexural strength in the sintered samples.

- The excessive addition of the polymeric additive in the high solid loading slurries resulted in an uneven pore structure in the freeze-dried sample and a decrease in the strength.

- The optimised formula of the slurries with a binder content of 5 wt. $\%$, a foaming agent of $5 \mathrm{wt} . \%$, and a solid loading of $60 \mathrm{wt}$ \% (B5F5_60) showed the fastest drying process and provided the highest porosity with adequate strength.

\section{Acknowledgments}

The authors would like to thank the National Metal and Materials Technology Center (MTEC), Thailand, for providing funding for this research and for providing the testing facilities. We are grateful for Prof. S. Seraphin (Professional Authorship Center, NSTDA) for his invaluable comments on the manuscript preparation.

\section{REFERENCES}

1. Araki K., Halloran J.W. (2004): New freeze-casting technique for ceramics with sublimable vehicles. Journal of the American Ceramic Society, 87, 1859-1863. doi: 10.1111/ j.1151-2916.2004.tb06331.x

2. Ahmad R., Ha J. H., Song I. H. (2014): Processing methods for the preparation of porous ceramics. Journal of Korean Powder Metallurgy Institute, 21, 389-398. doi: 10.4150/ KPMI.2014.21.5.389
3. Liu R., Xu T., Wang C. A. (2016): A review of fabrication strategies and applications of porous ceramics prepared by freeze-casting method. Ceramics International, 42, 2907-2925. doi: 10.1016/j.ceramint.2015.10.148

4. de Castro M. D. L., García J. L. L. (2002). Analytical freeze-drying, in Techniques and Instrumentation in Analytical Chemistry. Elsevier. pp. 11-41. doi: 10.1016/S01679244(02)80004-X

5. Fukasawa T., Deng Z. Y., Ando M., Ohji T., Goto Y. (2001): Pore structure of porous ceramics synthesized from waterbased slurry by freeze-dry process. Journal of Materials Science, 36, 2523-2527. doi: 10.1023/A:1017946518955

6. Chen Y., Wang N., Ola O., Xia Y., Zhu Y. (2021): Porous ceramics: Light in weight but heavy in energy and environment technologies. Materials Science and Engineering: R: Reports, 143, 100589. doi: 10.1016/j.mser.2020.100589

7. Tang X. C., Pikal M. J. (2004): Design of freeze-drying processes for pharmaceuticals: practical advice. Pharmaceutical research, 2, 191-200. doi: 10.1023/B:PHAM.00000 16234.73023 .75

8. Vanbillemont B., Nicolaï N., Leys L., De Beer T. (2020): Model-based optimisation and control strategy for the primary drying phase of a lyophilisation process. Pharmaceutics, 12, 181. doi: 10.3390/pharmaceutics 12020181

9. Nowak D., Jakubczyk E. (2020): The freeze-drying of foods - The characteristic of the process course and the effect of its parameters on the physical properties of food materials. Foods, 9, 1488. doi: 10.3390/foods9101488

10. Yao D., Xia Y., Zuo K. H., Zeng Y. P., Jiang D., Günster J., Heinrich J. G. (2015): Gradient porous silicon nitride prepared via vacuum foaming and freeze drying. Materials letters, 141, 138-140. doi: 10.1016/j.matlet.2014.11.067

11. Tomford W. W. (1993). Musculoskeletal tissue banking. Raven Press.

12. Hendrawan H., Khoerunnisa F., Sonjaya Y., Putri A. D. (2019): Poly (vinyl alcohol)/glutaraldehyde/Premna oblongifolia merr extract hydrogel for controlled-release and water absorption application. In IOP Conference Series: Materials Science and Engineering, 509, 012048. IOP Publishing. doi: 10.1088/1757-899X/509/1/012048

13. Pal K., Banthia A. K., Majumdar D. K. (2007): Preparation and characterization of polyvinyl alcohol-gelatin hydrogel membranes for biomedical applications. Aaps Pharmscitech, 8, E142-E146. doi: 10.1208/pt080121

14. Olewnik-Kruszkowska E., Gierszewska M., Jakubowska E., Tarach I., Sedlarik V., Pummerova M. (2019): Antibacterial films based on PVA and PVA-chitosan modified with poly (hexamethylene guanidine). Polymers, 11, 2093. doi: 10. 3390/polym 11122093

15. Al-Sabagh A. M., Abdeen Z. (2010): Preparation and characterization of hydrogel based on poly (vinyl alcohol) cross-linked by different cross-linkers used to dry organic solvents. Journal of Polymers and the Environment, 18, 576-583. doi: 10.1007/s10924-010-0200-5

16. Hafizah M. A. E., Riyadi A. F., Manaf A. (2019): Particle size reduction of polyaniline assisted by anionic emulsifier of sodium dodecyl sulphate (SDS) through emulsion polymerization. In IOP Conference Series: Materials Science and Engineering, 515, 012080. IOP Publishing. doi: 10. 1088/1757-899X/515/1/012080.

17. Gao X., Chorover J. (2010): Adsorption of sodium dodecyl sulfate (SDS) at $\mathrm{ZnSe}$ and $\alpha-\mathrm{Fe}_{2} \mathrm{O}_{3}$ surfaces: Combining 
infrared spectroscopy and batch uptake studies. Journal of colloid and interface science, 348, 167-176. doi: 10.1016/j. jcis.2010.04.011

18. Omonmhenle S. I., Shannon I. J. (2016): Synthesis and characterisation of surfactant enhanced $\mathrm{Mg}-\mathrm{Al}$ hydrocalcite-like compounds as potential 2-chlorophenol scavengers. Applied Clay Science, 127, 88-94. doi: 10.1016/j. clay.2016.03.033

19. Bruce C. D., Senapati S., Berkowitz M. L., Perera L., Forbes M. D. (2002): Molecular dynamics simulations of sodium dodecyl sulfate micelle in water: the behavior of water. The Journal of Physical Chemistry B, 106, 10902-10907. doi: 10.1021/jp025872x

20. Livingstone R. A., Nagata Y., Bonn M., Backus E. H. (2015): Two types of water at the water-surfactant interface revealed by time-resolved vibrational spectroscopy. Journal of the American Chemical Society, 137, 14912-14919. doi: 10.1021/jacs.5b07845

21. Boumaza A., Djelloul A., Guerrab F. (2010): Specific signatures of $\alpha$-alumina powders prepared by calcination of boehmite or gibbsite. Powder Technology, 201, 177-180. doi: 10.1016/j.powtec.2010.03.036
22. Steinbach G. (1971). Equations for the Heat and Mass Transfer in Freeze-Drying of Porous and Non-Porous Layers and Bodies. International Institute of Refrigeration (XIII), Washington.

23. Andrade R. D., Lemus R., Perez C. E. (2011): Models of sorption isotherms for food: uses and limitations. Vitae, 18 , 325-334

24. Wang F., Yin J., Yao D., Xia Y., Zuo K., Zeng Y. (2017): Porous $\mathrm{SiC}$ ceramics fabricated by quick freeze casting and solid state sintering. Progress in Natural Science: Materials International, 27, 380-384. doi: 10.1016/j.pnsc. 2017.04.006

25. Ciurans Oset M., Nordin J., Akhtar F. (2018): Processing of macroporous alumina ceramics using pre-expanded polymer microspheres as sacrificial template. Ceramics, 1 , 329-342. doi: 10.3390/ceramics 1020026

26. Tallon C., Moreno R., Nieto I. M. (2009): Shaping of porous alumina bodies by freeze casting. Advances in Applied Ceramics, 108, 307-313. doi: 10.1179/174367608X369280 